\title{
Role of Thymidinekinase and Thymidine Phosphorylase as Enzymatic Test for Efficacy of Oncological Patients Treatment
}

\author{
Berta G Borzenko*, Elena M Bakurova, Kseniia A Mironova, Yuliya D Tursunova and Yuriy V Dumanskiy
}

Department of Chemistry, Maksim Gorky Donetsk National Medical University, Donetsk, Ukraine

\begin{abstract}
The treatment of breast cancer has been undergoing an incredible sequence of changes. The role of individual treatment of women with breast cancer is not clearly defined. Since last century the drug 5-fluorouracil with another anticancer agents and prodrugs from group of fluoropyrimidines are widely used. Thymidine phosphorylase is the enzyme which can also catalyze the interconversion of uracil as well as several fluoropyrimidines. Thymidine Phosphorylase (TP) and Thymidine Kinase (TK) also play an important role in thymidine homeostasis and thus in DNA synthesis. Thymidine kinase is used as cells proliferation marker. Thymidine phosphorylase is similar to the platelet-derived endothelial cells growth factor. High expression of the enzyme is related to malignant angiogenesis and invasion. That is why we investigated the activity of TK and TP both in healthy women and patients with breast cancer (BC) of the I-IV stages and of the same age. Analysis of biochemical and morphological data of these patients revealed that the patients are initially divided according to the activity of blood plasma TP also had different morphological structure of the tumor. In the 1-st group the initial activity of TP was sharply reduced and in the $2^{\text {nd }}$ group TP activity ranged normally. During the treatment of women from the $1^{\text {st }}$ group the activity of TP was not changed, but the activity of TK was increased 3 times. In patients from the $2^{\text {nd }}$ group the activity of TP was authentically increased, but TK activity was reduced. The follow-up analysis showed that four-year lethality in the 1 -st group constituted $25 \%$, and there was no lethality in the the $2^{\text {nd }}$ group. Therefore the studied enzymes activity may be used as the informative test for monitoring of patients with breast cancer and optimization of drug treatment.
\end{abstract}

Keywords: Breast cancer; Treatment; Thymidine kinase; Thymidine phosphorylase; Blood plasma

\section{Introduction}

Breast cancer, the most common cancer and the second leading cause of death in women [1]. This disease is in constant evolution and requires, more than ever, a fully integrated multidisciplinary management, as well as an ongoing dialogue with laboratory scientists. As a result of this evolution, medical oncologists, surgeons, biochemists, pathologists are facing new challenges in the optimal breast cancer management. It is now clear that breast cancer may be more or less aggressive and that several prognostic and predictive factors may play a major role in the choice of the most appropriate therapy and in the final results.

The main question to be considered is about the role of post mastectomy drug. 5- Fluorouracil (5- FU) has been used for the treatment of breast cancer for more than 30 years and during this time it has been the subject of extensive research about the optimization of its use. The importance of tumor proliferation in determining response to chemotherapy treatment has been clearly establishment in breast cancer. The proliferation rate of breast cancer has been analyzed with various methods such as the S-phase fraction or Ki-67 index that do not discriminate between de novo and "salvage" pathways of pyrimidine synthesis. Pyrimidine incorporation is the limiting step for DNA synthesis. The "salvage pathway" ensures that the pyrimidine nucleotides pool is very important for the efficient DNA replication. Thymidine kinase (TK, EK 2.1.2.1.) and thymidine phosphorylase (TP, EK 2.4.2.4.) are key enzymes of this metabolic process. In the "salvage pathway" TK directly catalyzes the phosphorylation of deoxythymidine released by DNA catabolism [1]. TP was the first purified and characterized as an enzyme involved in nucleic acids homeostasis. A role of TP in nucleic acids metabolism was well known, but later the importance of this enzyme in angiogenesis was also discovered [2,3]. It was shown that TP is similar to platelet-derived endothelial cell growth factor (PD-ECGF) and hence plays a dual role in cell biology. It has been postulated that the angiogenesis effect of $\mathrm{PD}-\mathrm{ECGF} / \mathrm{TP}$ is related to the enzymatic activity of TP. Expression of both enzymes TK and $\mathrm{TP}$ has been associated with the proliferation of breast cancer cells both in vitro and in vivo. Their high expression was revealed also in angiogenesis and invasion and therefore it leads to a poor prognosis $[4,5]$. TP takes part in a lethal synthesis of 5-FU in human tumors [6].

The new criteria of tumors sensitivity to chemical drugs necessary for oncology patients chemotherapy has being intensively developed. The enzymes of DNA precursors metabolism are of great interest because these metabolites are widely used as chemotherapeutic drugs.

The aim of our study was to investigate blood plasma activity of TK and TP in women with breast cancer depending on age and stage of the disease for further estimation of chemotherapy efficacy and prognosis of tumor progression.

\section{Materials and Methods}

94 patients with breast cancer (BC) of I-IV stages were studied. Among all patients, aged between $46-60$ years stage I of BC was

*Corresponding author: Berta Georgievna Borzenko, Department of Chemistry, M. Gorky National Medical University, Pr. Illicha 16, Donetsk, 83003, Ukraine, Tel: 067-621-25-75; E-mail: borzenko.bg@rambler.ru

Received July 09, 2013; Accepted August 27, 2013; Published September 02, 2013

Citation: Borzenko BG, Bakurova EM, A Mironova K, Tursunova YD, Dumanskiy YV (2013) Role of Thymidinekinase and Thymidine Phosphorylase as Enzymatic Test for Efficacy of Oncological Patients Treatment. Metabolomics 3: 123. doi:10.4172/2153-0769.1000123

Copyright: () 2013 Borzenko BG, et al. This is an open-access article distributed under the terms of the Creative Commons Attribution License, which permits unrestricted use, distribution, and reproduction in any medium, provided the original author and source are credited. 
Citation: Borzenko BG, Bakurova EM, A Mironova K, Tursunova YD, Dumanskiy YV (2013) Role of Thymidinekinase and Thymidine Phosphorylase as Enzymatic Test for Efficacy of Oncological Patients Treatment. Metabolomics 3: 123. doi:10.4172/2153-0769.1000123

Page 2 of 3

diagnosed in 11 patients, II stage - in 12 patients, III stage - in 35 patients and stage IV - in 15 patients. What's more, aged between 36 - 45 years stage III of BC was diagnosed in 9 patients and stage IV - in 12 patients. 52 healthy women were studied as a control. Among them, 10 women aged between $25-35$ years, 13 women between $36-45$ years, 19 women between 46-60 years and 10 women between 61-70 years. The study protocol was approved by Ethical Committee permission of M. Gorky Donetsk National Medical University for studies with human materials. The oncological patients' blood plasma had been examined before and after the initial surgical resection and then every other 5 days during postoperative chemotherapy. The patients were followed-up during 4-5 years. TK activity was determined by the radioisotope method as described previously [1]. Radioactivity of diethyl-amino-ethyl-cellulose paper disks (DEAE-cellulose disks paper "Limbro", UK) was counted in a liquid scintillation SL-8 on a biological scintillation counter (CBS-2, Russia). TK activity is represented in tables in nanomoles of thymidylate produced within an hour per 1 $\mathrm{mg}$ of protein. TP activity was determined spectrophotometrically at $300 \mathrm{~nm}$ according to the amount of thymine formed [2]. From each supernatant, $0.02 \mathrm{ml}$ of it was incubated with $50 \mathrm{mM}$ potassium phosphate buffer and $10 \mathrm{mM}$ thymidine («Sigma», Germany) in a total volume of $1 \mathrm{ml}$. After incubation for $30 \mathrm{~min}$ at $37^{\circ} \mathrm{C}$, the reaction was terminated by boiling and adding $2.5 \mathrm{ml}$ of $0.1 \mathrm{M} \mathrm{NaOH}$. The activity of TP is represented in nanomoles of thymine generated per $1 \mathrm{~min} / \mathrm{mg}$ of protein. Protein concentration in biological material was determined by Lowry method [7]. Statistical analysis of results was performed using computer "Medstat" software package. The significance of differences was analyzed by parametric (Student test) and nonparametric (the index of Spearman`s rank correlation test, rho) methods.

\section{Results and Discussion}

According to the results of our previous studies [1,2], the activity of serum enzymes correlates with their activity in the tissues. Our findings comply with the results of other authors [8]. In present study the enzymes activity values in blood plasma of patients with BC, and in blood plasma of control group were determined (Table 1). According to our data TK has highest level of its activity in the plasma at the age of 46-60 years. The relationship between parameters was assessed statistically using Spearman's rank correlation test (rho). Positive correlation between TK activity and the age of the control group women was revealed $(r h o=0.519)$. Therefore, we determined the increase of TMP synthesis by the "salvage pathway" in healthy individuals in the age of 46-60 years.

The activity of TP was also age-dependent (the index of Spearman's rank correlation, i.e. rho $=0.874$ ). It is interesting to note that direct correlation between the anabolic and catabolic enzymes activity (TK, $\mathrm{TP})$ can regulate the rate of dTTP synthesis by the "salvage pathway" in healthy people.

It has been determined that in case of breast cancer development the age-dependent property of TP activity was lost. A negative correlation between the TP activity in the blood plasma and age was exposed (rho=-0.415). In this case the increasing of TK activity was accompanied by decreasing of TP activity in the plasma of patients with BC. This disorder may be one of the reasons of the increasing dTTP synthesis and higher rate of proliferation.

The present findings show that TK activity increases according to the stage of illness (Table 2). On the contrary, changes of TP activity in blood plasma had opposite direction. The minimal activity of TP was shown at the IV stage of the disease. According to our opinion the

\begin{tabular}{|c|c|c|c|c|}
\hline \multirow{2}{*}{ Age, years } & \multicolumn{2}{|c|}{ TK nmol/mg·h } & \multicolumn{2}{c|}{ TP nmol/mg $\cdot \mathrm{min}$} \\
\cline { 2 - 5 } & Control (healthy) & BC & Control (healthy) & BC \\
\hline $25-35$ & $2,01 \pm 0,04$ & - & $35,58 \pm 3,01$ & - \\
\hline $36-45$ & $1,79 \pm 0,35$ & $3,58 \pm 0,45^{\star}$ & $44,12 \pm 3,45$ & $23,87 \pm 3,76^{\star *}$ \\
\hline $46-60$ & $3,14 \pm 0,49$ & $4,62 \pm 0,28^{*}$ & $48,34 \pm 3,23$ & $27,60 \pm 3,60^{\star *}$ \\
\hline $61-70$ & $1,55 \pm 0,25$ & $2,95 \pm 0,89^{*}$ & $51,67 \pm 3,12$ & $16,82 \pm 2,56^{\star *}$ \\
\hline
\end{tabular}

Note: authentic differences versus the norm: ${ }^{*}-p<0,05,{ }^{* *}-p<0,01$

Table 1: The salvage thymidilate synthesis enzymes activity in serum in control group and III stage breast cancer patients at the different age.

\begin{tabular}{|c|c|c|}
\hline Studied & TK & TP \\
\hline Healthy & $3,14 \pm 0,49$ & $48,34 \pm 3,23$ \\
\hline BC I stage, $\mathrm{n}=11$ & $3,92 \pm 0,01^{*}$ & $36,00 \pm 1,20$ \\
\hline BC II stage, $\mathrm{n}=12$ & $3,98 \pm 0,04^{\star *}$ & $33,60 \pm 1,20^{*}$ \\
\hline BC III stage, $\mathrm{n}=35$ & $4,62 \pm 0,28^{\star *}$ & $27,60 \pm 3,60^{\star *}$ \\
\hline BC IV stage, $\mathrm{n}=15$ & $4,94 \pm 0,14^{\star *}$ & $18,00 \pm 1,20^{\star *}$ \\
\hline
\end{tabular}

Note: - authentic differences versus the norm: ${ }^{*}-p<0,05,{ }^{* *}-p<0,001$; from 9 to 35 patients were determined in each group

Table 2: Activity of thymidine and adenosine metabolism enzymes in the blood of healthy women and I-IV stage BC at the age of $46-60$ years, (nmol/ $\mathrm{mg} \cdot \mathrm{min}$ ).

revealed changes of both enzymes activity can cause activation of DNA biosynthesis by the "salvage pathway".

It is known that metabolic features of tumors can be due to their ability to express the embryonal forms of the enzymes. In particular, it was shown the existence of several cellular forms of thymidine kinase [2]. Cytoplasmic thymidine kinase is named "embryonal" isozyme. It has, from mitochondrial isozyme, different physical and chemical properties. It is TK "embryonic" that can phosphorylate thymidine for the synthesis of nuclear DNA, and its activity is directly correlating with the cellular proliferation rate. Some kinetic TK properties in patients with BC were studied in comparison with the norm. It has been determined that TK maximum activity peak has differed from physiological one (Figure 1). As the maximum TK activity of blood plasma of healthy people of different age is registered at $20^{\text {th }}$ minute of incubation in the reaction medium $(3.97 \mathrm{nmol} / \mathrm{mg} \cdot \mathrm{h})$. The oncological patients plasma TK activity maximum is registered at $30^{\text {th }}$ minute $(5.86 \mathrm{nmol} / \mathrm{mg} \cdot \mathrm{h})$. The obtained data can be probably associated with the increase of the "embryonal" isozyme expression, as it has been established that tumor isozyme is determined not only in tissues, but in patients' blood as well.

To reveal prognostic possibilities of the studied enzymes activity we created the group of patients ( 29 women) of both similar age (46-60 years old) and stage of BC (III stage of BC). We investigated TP and TK activity after the initial surgical resection and every 5 th day during postoperative chemotherapy by CMF scheme (Table 3 ). This scheme includes cyclophosphamide, methotrexate, 5 -fluorouracil.

Individual analysis of the enzymes activity in blood plasma of all 29 patients allowed dividing them into two groups. Group 1 consisted of 15 patients with low activity of TP before the drug therapy (13.20 \pm 3.60 $\mathrm{nmol} / \mathrm{mg} \cdot \mathrm{min})$. Group 2 included 14 patients. Their TP activity was similar with normal: $43.20 \pm 3.60 \mathrm{nmol} / \mathrm{mg} \cdot \mathrm{min}$. During chemotherapy the TP activity in group 1 was not changed but the activity of TK was increased. It may stimulate the rate of proliferation resulted in the poor prognosis. Simultaneously in group 2 the activity of TK was decreased but the activity of TP was increased. The analysis of morphological material from these patients showed that the patients initially divided by the principle of the activity of blood plasma TP also differ by morphological structure of tumor. Scirrhous carcinoma, or cancer with 
Citation: Borzenko BG, Bakurova EM, A Mironova K, Tursunova YD, Dumanskiy YV (2013) Role of Thymidinekinase and Thymidine Phosphorylase as Enzymatic Test for Efficacy of Oncological Patients Treatment. Metabolomics 3: 123. doi:10.4172/2153-0769.1000123

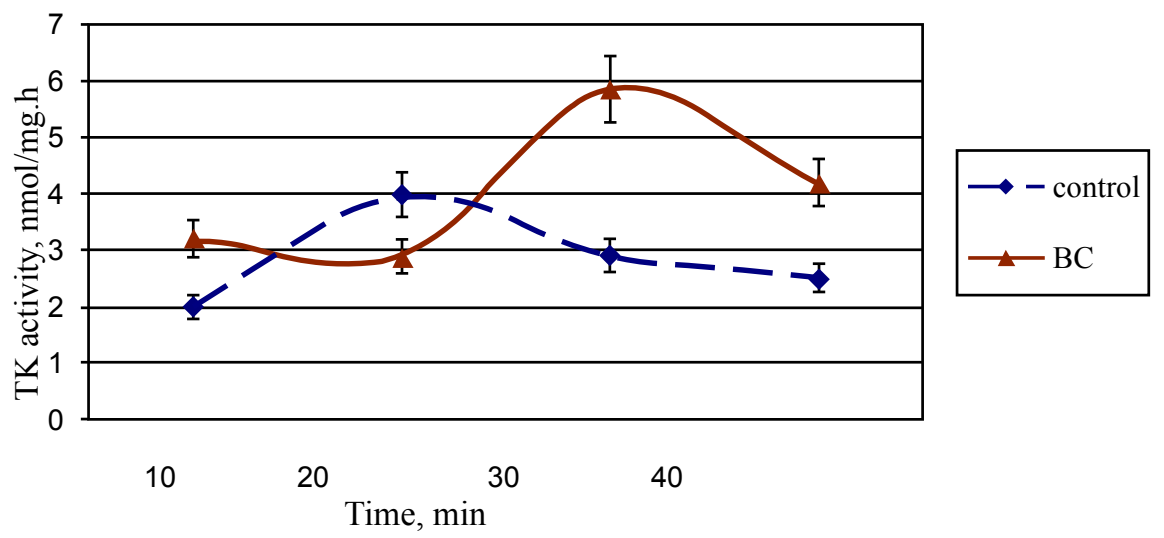

Figure 1: Effect of different time of incubation on the thymidine kinase activity in the blood serum of control group, patients with stomach cancer at the age of $46-60$ years $(\mathrm{nmol} / \mathrm{mg} \cdot \mathrm{h}): 1-10 \mathrm{~min} ; 2-20 \mathrm{~min} ; 3-30 \mathrm{~min} ; 4-40 \mathrm{~min}$.

\begin{tabular}{|c|c|c|c|c|c|c|c|c|}
\hline & \multicolumn{4}{|c|}{$\mathrm{TK}, \mathrm{nmol} / \mathrm{mg} \cdot \mathrm{h}$} & \multicolumn{4}{|c|}{$\mathrm{TP}, \mathrm{nmol} / \mathrm{mg} \cdot \min$} \\
\hline & \multirow{2}{*}{ Before } & \multicolumn{3}{|c|}{ CMF treatment (Days) } & \multirow[t]{2}{*}{ Before } & \multicolumn{3}{|c|}{ CMF treatment (Days) } \\
\hline & & 5 & 10 & 15 & & 5 & 10 & 15 \\
\hline Gr.1, n=15 & $3,14 \pm 0,95$ & $1,67 \pm 0,34$ & $3,22 \pm 0,61$ & $9,16 \pm 1,22$ & $13,20 \pm 3,60$ & $20,40 \pm 6,00$ & $15,60 \pm 3,60$ & $19,20 \pm 6,00$ \\
\hline Gr.2, n=14 & $2,97 \pm 0,34$ & $1,05 \pm 0,06$ & $1,13 \pm 0,02$ & $1,85 \pm 0,67$ & $43,20 \pm 3,60$ & $39,60 \pm 6,00$ & $39,60 \pm 4,80$ & $55,20 \pm 1,20$ \\
\hline
\end{tabular}

Table 3: The enzyme activity dynamics in the blood serum of women with BC before and during CMF treatment.

prevalence of stroma, was developed in patients with low blood plasma TP activity (Group 1), and adenocarcinomas of various differentiations were developed in patients with normal TP activity (Group 2).

The follow - up analysis showed that four-year lethality in group 1 constituted $25 \%$ and there was no lethality in group 2 . Thus our findings demonstrate that the dynamics of TK, TP activity can be used as the biochemical test for individual estimation of both tumor progression and drug therapy efficiency.

\section{Conclusion}

Such prognostic factors as blood plasma activities of TK and TP may be used for the decision-making about efficiency of 5-fluorouracil for patients with breast cancer.

\section{References}

1. Borzenko BG, Bakurova EM (2007) Violation of the metabolism of DNA precursors in gastric mucosa as an indicator of likely malignancy ulcers of the body. Questions of Oncology 54: 184-187.

2. Borzenko BG, Bakurova EM, Popovich YuA, Sidyuk EA, Popovich AU (2013) Activity of thymidilate "salvage pathway" enzymes in human gastric cancer and blood serum: correlation with treatment modalities. Exp Oncol 35: 37-40.

3. Brockenbrough JS, Morihara JK, Hawes SE, Stern JE, Rasey JS, et al. (2009) Thymidine kinase 1 and thymidine phosphorylase expression in non-smallcell lung carcinoma in relation to angiogenesis and proliferation. J Histochem Cytochem 57: 1087-1097.

4. Grimminger PP, Schneider PM, Metzger R, Vallböhmer D, Hölscher $A H$, et al. (2010) Low thymidylate synthase, thymidine phosphorylase, and dihydropyrimidine dehydrogenase mRNA expression correlate with prolonged survival in resected non-small-cell lung cancer. Clin Lung Cancer 11: 328-334.
5. Kawahara A, Akagi Y, Hattori S, Mizobe T, Shirouzu K, et al. (2009) Higher expression of deoxyuridine triphosphatase (dUTPase) may predict the metastasis potential of colorectal cancer. J Clin Phathology 62: 364 -369.

6. Lubner SJ, Loconte NK, Holen KD, Schelman W, Thomas JP, et al. (2010) A Phase II study of Oxaliplatin, 5-Fluorouracil, Leucovorin, and high-dose Capecitabine in patients with metastatic colorectal cancer. Clin Colorectal Cancer 9: 157-161.

7. Lowry OH, Rosenbrough NJ, Farr AL, Randall RJ (1951) Protein measurement with the Folin phenol reagent. J Biol Chem 193: 265-275.

8. Kubiak R, Miszczak-Zaborska E, Smolarek M, Wójcik-Krowiranda K, Bartkowiak $J$ (2009) The thymidine phosphorylase as the platelet-derived endothelial cell growth factor of endometrial cancer. Ginekol Pol 80: 596-601. 